\title{
Impact of Sales Tax Reduction on Pakistan`s Economy
}

\author{
GHULAM MOEEN-UD-DIN ${ }^{1}$, HASNAIN ABBAS NAQVI ${ }^{2}$, MUHAMMAD AZHAR KHAN ${ }^{3}$ \\ ${ }^{1}$ Department of Economics, Punjab College of Commerce, Blue Area, Islamabad, PAKISTAN. \\ E-mail: prof.moeenuddin.eco@gmail.com \\ ${ }^{2}$ Assistant Professor, UNIVERSITY OF HAFR-ALBATIN, KINGDOM OF SAUDI ARABIA. E-mail: hnaqvi@uhb.edu.sa \\ ${ }^{3}$ Assistant Professor, UNIVERSITY OF HAFR-ALBATIN, KINGDOM OF SAUDI ARABIA. \\ E-mail: mazhark@uhb.edu.sa
}

\begin{abstract}
This paper studies the impact of reducing sales tax on macroeconomic variables like gross domestic product, national income, imports, exports, the balance of trade, private and public sector investment in the economy of Pakistan by using computable general equilibrium (CGE) model on the country's latest available social accounting matrix (SAM) 2010-11. Previous studies have been designed to isolate to impact of indirect (sales) tax on some single, two, or three variables of the economy whereas, this investigation covers the impact on almost all the major macroeconomic indicators in context of one model. To examine the impact, simulations of $5 \%$ and $10 \%$ reductions on eminent macroeconomic indicators are performed. The experiment shows positive impact on all the above mentioned variables except a very few. In the light of these observations, our study recommends that policy of reducing sales tax should steadily be implemented in order to achieve economic development and maintain macroeconomic stability in the economy of Pakistan.
\end{abstract}

Keywords: Sales Tax, Macroeconomic Indicators, Computable General Equilibrium Model, Social Accounting Matrix, Macroeconomic Stability.

JEL Classification: C15, C68, D02, E16, F62, F63, H2, P24, P33 


\section{Introduction}

Economic inequality can be reduced through appropriate changes in tax structure. Decrease in indirect taxes can be an effective strategy to reduce the gap between haves and have nots. The households with low income group can get relief of increase in their real income through this fiscal instrument not only in increasing in their purchasing power but also in power to save, which ultimately results into improvement of the investment level in the country. This sort of injection results into creating employment opportunities and welfare improving steps in the economy. The core aim of this study is the same to see that up to what degree the simulation experiment point outs this positive impact on the households of different categories. For this purpose Pk-SAM 2110-11 over 172 X 172, developed by Dorosh et al. (2015) for the economy of Pakistan is considered here, and Static Computable General Equilibrium Model is applied to come up with the results. To achieve a sustainable economic development, budget deficit should be reduced to zero, which is a very severe matter in Pakistan's budget history. Accordingly, poverty and inequality multiplies, welfare recedes, and a large number of significant aggregative economic indicators depreciate. Which is an obstruction in the way of economy`s development. Budget deficit can be supported through more inflationary way, i.e., borrowing or deficit financing, usually. But suitable changes in tax structure, especially reducing indirect taxes, can produce the required results in better way too, as the present analysis presents. The fiscalists adjust the savings, investments, with effect on productivity, a labor force that indicates significant elements in economic strategy that produce fiscal reform as an imperative measure of the economic reforms.

The aim of this simulation test is to estimate the impacts of reducing sales tax on some major macroeconomic variables like GDP, national income, imports, exports, balance of trade, private and public sector investment of the economy of Pakistan.

\section{Literature Review}

The query that whether adjustments in the indirect taxes influence macroeconomic signs has been extensively examined in the literature regarding fiscal policy. Taxes, directly or indirectly affects the proclivities or affinities of the households related to their all economic activities, like earning, spending, saving, and investing. Empirical investigations on this line that whether changes in indirect taxes like reduction in sales tax promotes growth rate of the economy and achieve economic stability. To stimulate all these goals efficient steps to implement this tool are needed for the economic condition of Pakistan.

The believers of the endogenous growth models do not believe in external factors for growth (Fadare, 2010). Reduction in indirect taxes results into improvement in real income which leads to increase in consumption and hence welfare, and also increase at the same time in savings and ultimate in investment which reduces unemployment and thus inequality and hence all this results into economic stability. Neo-classicals argues that all this will change capital-output ratio and so the production path as well as steady-state growth rate (Barro et al. 1991). Endogenously, taxation affects growth permanently (Bleaney et al. 2000). Papageorgiou (2012) analyzed the macroeconomic and welfare effects of variations in the tax- payments mix and debt- absorption policies in the Greek economy and concluded positive results on growth and welfare.

Paulson and Kaplan (2008) investigated that top marginal tax rates and direct tax too significantly adverse growth impact in USA. Higher the regressivity confirmed assenting growth affect. Arisoy and Unlukaplan (2010) analyzed the effect of the composition of direct-indirect tax on growth of Turkey, and concluded that share of direct taxes should be more than indirect taxes. A. A. Bhatti, Zakia B. and H. A. Naqvi (2015) employed two sets of simulations to examine the effect of taxes and transfers on inequality and found that sales tax or transfers alone can affect the pattern of income distribution, although at the same time it declines budget deficit. Similarly, the same researchers (2015) examined in their another study and found that Fiscal policy can effect on eliminating the gap between rich and 
poor directly as well as indirectly. The tools of fiscal policy directly affects the individual's disposable income, while indirectly their forthcoming income capacities.

Dehghan and Nonejad (2015) investigated the impact of corporate taxes, business taxes, and indirect taxes on economic growth of Iran by utilizing the data from 1981-2010 and using least squares method. The study found negative effect. Phiri (2016) investigated for South Asia for the period of 1990:Q1 to 2015:Q2, that there was positive relation between indirect taxes and economic growth, whereas direct taxes were found negatively related. While, Nmesirionye, J. A. et al. (2019) examined the effect of indirect taxes on Nigerian economy`s performance for the period 1994-2017 by adopting ex-post-facto research technique. The results reveals that VAT as well as custom and excise duties positively and significantly affect the real GDP.

For Pakistan, Mashkoor et al., (2010) also examined the data from 1973 to 2008 for the economy of Pakistan through ARDL approach that direct taxes to GDP ratio reasoned the real GDP growth. Hasnain A. Naqvi (2011) investigated the impact of imposition of agricultural income tax, and decrease in sales tax rates on Pakistan, and concluded that the it is favorable to boost households' as well as then economy's welfare. Similarly, Iqbal, et al. (2015) analyzed a data from 1979 to 2010 for the economy of Pakistan and found positive impact of general taxation on country's growth. Similarly, Shahzad A. et al. (2018) examined ARDL to find the relationship between indirect taxes and economic growth in Pakistan on annual time series data (1974-2010) and concluded that it is necessary to reduce indirect taxes while increase direct taxes for boosting up the economic growth. Presently, the contribution of indirect taxes is $63 \%$ out of total tax revenue, which indicate a small percentage of direct taxes. So it should be reversed to augment the rate of growth.

\section{Estimation Technique}

Modeling technique adopted in this testing is Computable General Equilibrium (CGE) to measure the shocks of reducing sales tax on overall economic pattern of Pakistan economy. This phenomenon of analyzing a comprehensive and steadfast statistical matrix formed input-output data facts about prominent sectors like; households types, commodities, institutions, and factors, is concordant with the static model structure designed by Lofgren et al (2002). The most latest Social Accounting Matrix (SAM) 2010-11 for economy of Pakistan is considered as benchmark, which is developed by Dorosh et al (2015). This SAM is over $172 \times 172$ matrix form, which is segregated into $47 \times 47$ matrix structure for this analysis. The challenges facing the economy are identified by the help a comprehensive set of equations for CGE Modeling. Applying General Algebraic Modeling System (GAMS) on data and finding the results, this study recommends the policies to solve the questions in point. The equations of this model authenticate the satiety of measure regarding outputs and factors markets, savings and investment, government, and current account balances. This analysis does not use second period changes because of a standard static technique. The equations created for this model express the interrelatedness of the entire economy.

The SAM shows real aggregates for the coefficients in designed equalities due to a system of measurement. It is initially elucidated for equilibrium, then shocked with amendment in the values of the variables chosen exogenously. In the next step it is solved once more for the values of equilibrium and endogenous changes. Lastly, the results are matched with the equilibrium values of base period and in this manner, the effect of exogenous shocks is calculated.

The SAM 2010-11 includes sixty four activities, sixty three commodities, twelve factors of production, sixteen forms of households, and seventeen other important accounts. To ease the analysis all these are simplified and reduces to nine activities, nine commodities, three factors of production, ten other important accounts except households. In this way the matrix condensed from $172 \times 172$ to $47 \times 47$.

In this moderated matrix form table Nine Activities and Commodities are Agriculture, Mining, Food Manufacturing, Cotton Lint/ Yarn, Textile. Leather, Other Manufacturing, Energy and Services, the factors of production are Labor, Land, and Capital, the households forms are Rural Small farmers 
(Quartile-1, and -234), Rural Medium Farmer (Quartile-1, and -234), Rural Landless Farmer (Quartile1, and -234), Rural Farm Workers (Quartile-1, -2, -3, and -4), Rural Non-Farm (Quartile-1, and -234), and Urban (Quartile-1, -2, -3, and -4). Whereas, other accounts consists Transaction, Enterprise, Government, Subsidies, Sales Tax, Import Duty, Rebate, Direct Tax, Saving-Investment, and Rest of the World. In SAM 2010-11, symbolically the activities and commodities are represented by AGRI, MINE, FMAN, YARN, TEXT, LEAT. MANF, ENRG, and SER, Factors of production by LAB, LND, and CAP, Households by H-RS1, H-RS234, H-RM1, H-RM234, H-RL1, H-RL234, H-RW1, H-RW234, H-RN1, H-RN2, H-RN3, H-RN4, H-U1, H-U2, H-U3, and H-U4, and other accounts by TRC, ENT, GOV, SUB, STAX, MTAX, ETAX, DTAX, S-I, and ROW, respectively.

\subsection{Blocks of the Equations}

The CGE Model comprises four blocks like; price block, production and commodity block, institution block, and system constraint block. All these blocks contains sets of the equations. Equations can be provided on request.

\subsubsection{Price Block}

This block incorporates the equation's set of the model comprises endogenous/ exogenous prices and non-price variables. Activity`s manufacturer price $(\mathrm{PX})$ comprises taxes in the production process. Similarly, export price (PE) includes taxes on exports and import price (MP) embraces after taxes on imports. Composite commodities prices $(P Q)$ is verified by the interaction in domestic and import prices. Moreover, $\mathrm{PQ}$ also includes sales tax, which enables to attain final market price of the product.

\subsubsection{Production and Commodity Block}

The activities obtain rewards after selling output and spend it on buying inputs and/ or paying wages or rent to the basic intermediate factors. All the activities are assumed as profit maximizers, which is subject to the output function, substitutability and their fixed coefficient. Maximization of the profit is also subject to constant returns to scale. Producers picks inputs on constant elasticity of substitution (CES), which lets them to response to the comparative input returns variations. The factors obtain rewards as per the principle of equality in their marginal cost and marginal revenue (MC=MR), finalized on the core of endogenous relative prices.

In the CGE Modeling, by applying Leontief order, factors of production are joined with fixed share intermediates and hence decides the technique of production. Likewise, the model suppose that only one product can be produced by each activity. Production and Commodity block covers the employment input and domestic output, allocation of domestic output to domestic and foreign markets, and aggregation of domestic market supply. For constant elasticity of substitution (CES), Cobb-Douglas production function is used to realize the association between input and activity levels.

\subsubsection{Institutions Block}

Institutions block contains the main institutions like; Households, Enterprise, and Government. Rewards of the factors are contribution to value added because land, labor, and capital are owned by the households. Rewards of land and labor are divided up across two households' groups, whereas reward of the third factor delivered also to the enterprises and government as a part of primary capital endowment. Public revenue includes taxes on factors transfers from abroad, while public outlay are total spending on consumption and transfers. Enterprises 'income source is return on capital, later the enterprises make payments to swathe savings and transfers while it is inferred that enterprises do not consume the goods. Similarly, government spend its income earned from direct as well as indirect taxes on its consumption issues as well as transfers. Capital, which is fixed in real term, is also the source of public revenue. Budget is balanced only if public income and outlay are equal. If there is budget deficit, it is financed through capital market of the country. Public authority play its role as a 
consumer in CGEM-Pk. Public outlay are fixed, whereas its transfers are CPI indexed, i.e., fixed in nominal terms.

\subsubsection{System Constraint Block}

For macroeconomic stability, behavioral equation are formed with some constraints as per requirement of the structure where the indicators adjusts. The economy keeps only one option for such parameters. Supply of the factors must be equal to their demand in all the activities. Equally, spending and earning equivalence is also imposed on balance of the current account for rest of the world. Likewise, constraint of saving-investment is avowed too. An elastic scalar over non-public organization is multiplied by savings rates to operate this balance.

\subsubsection{Price Normalization}

Computable General Equilibrium Model is zero degree homogeneous hypothesis. The equation of price normalization in this standard is created to verify one specific solution, which improves the CPI measures.

\subsection{Model Closure}

The Model covers exogenous and endogenous, both types of the variables. At equilibrium number of endogenous variables always identical to the numeral of equations. To run the simulations, closure avows macroeconomic assumptions, which are attained because of changes in exogenic values of the variables considered in model and in this mode the effect on equilibrium is measured. The model assumes savings from abroad as fixed and thus to clear the current account, flexible exchange rate is operated. Saving-driven-investment is supposed to support saving-investment account. As saving is considered as fixed therefore flexile factors facilitates investment to tweak correspondingly. The model specify the 'Capital' as a main factor in all the activities and deem capital as completely active and activity-precise, that is, capital market can cleared by adjusting the fixed price of capital and factorprice distortion.

\section{Data and Sources}

To analyze Pakistan economy, Dorosh et al. (2015) modeled 172X172 Social Accounting Matrix (SAM) for the year 2010-11 is used, which is the latest till now. This SAM includes 64-activities, 63commodities, 12-factors, 16-households types, and 17-other accounts. For present analysis, this SAM is segregated into $47 \times 47$, consisting 9-activities, 9-commodities, 3-factors, 16-households types, and 10-other accounts. The SAM denotes expenditures (column-wise) and income (row-wise). It satisfies the criterions and aspects of CGE Model for Pakistan (CGEM-Pk).

\subsection{Structure of Social Accounting Matrix 2010-11}

SAM 2010-11 presents inclusive sector wise contour of the Pakistan economy and displays the association among consumption, investment, and production. It frames key accounts like; A1-A9 Activities, C1-C9 Commodities, F1-F3 Factors, H1-H16 Households, and others; for example, Transaction Cost, Enterprises, Government, Subsidies, Sales Tax, Import Tax, Direct Tax, Saving/Investment, and Rest of the World. Lastly, SAM shows "Total" of the rows as well as columns. The only product that can neither be exported nor imported, is "Energy". It is domestic product to consume domestically.

The columns steered by GOV and S-I and ROW against C1-C9 in row articulates indirect taxes, investment spending on commodities, and foreigners' imports from Pakistan respectively. Factor account shows rewards and sources along with its distribution to the households, enterprises, institutions, and government. $\mathrm{H} 1-\mathrm{H} 12$ types of households are organized as per their land ownership while $\mathrm{H} 13-\mathrm{H} 16$ are classed as living in urban area. Savings and transfers to the institutions are the enterprises' expenditure. Enterprises attain gross profit on their capital account. Government account 
indicates her expenditure on consumption, transfers to the institutions, and savings as well as income from direct taxes, indirect taxes, and transfers from institutions, which is confirmed by the columns and rows headed by GOV. capital account evidences that how the investment is financed by institutions' savings. ROW beside C1-C9 column also means world's income, as it represents exports and imports of Pakistan. S-I column denotes income and expenditure equality of ROW by means of savings from abroad in capital account, which indicates current account balance.

\subsection{Trade Elasticities}

The intensity of domestic product's substitution with foreign products is gauged by using Armington elasticity. Low elasticity signals imported products as less reliable substitute for domestic product and vice-versa.

\section{Results of the Experiments}

To measure the influence of decreasing sales tax on macroeconomic indicators of the economy of Pakistan, three tests are conducted. The sectoral and macro outcomes of the simulations are described here. Simulation-I is experimented by $5 \%$, whereas, Simulation-II by $10 \%$.

\subsection{Effects Decrease in Sales Tax on Macroeconomic Indicators}

Impact of decreasing sales tax appears positive on all the macroeconomic indicators except investment, imports, and net indirect taxes. Table reveals that in both the simulations, GDP increases by $(0.326 \%, 0.653 \%)$ at factor cost, $(0.095 \%, 0.189 \%)$ at market prices from spending side, and $(0.068 \%$ and $0.136 \%$ ) at market price from income side respectively. Government consumption increases by $(0.042 \%)$ in Experiment-I while $(0.085 \%)$ in Experiment-II.

Likewise, exports augmented by $(0.334 \%)$ in Test-I and $(0.669 \%)$ in Test-II. Consumption in private sector is also grown by $(0.149 \%)$ and $(0.299 \%)$ in both simulations. An increase in imports by $(0.261 \%)$ in experiment-I and (0.524\%) in experiment-II also denotes a satisfactory signal for the adjustment in the balance of payments. Consequently, the effect on external trade is favorable. Reducing sales tax affected adversely the investment by $(0.264 \%)$ in Simulation-I $(0.534 \%)$ in Simulation-II, whereas, the net indirect taxes by $(3.457 \%)$ in Test-I and (6.934\%) in Test-II.

Table 01: Nominal GDP Data: (National Income Accounts)

\begin{tabular}{|c|c|c|c|c|c|}
\hline \multirow{2}{*}{ Variable } & \multirow{2}{*}{ Base } & \multicolumn{2}{|c|}{ Simulation-I [5\%] } & \multicolumn{2}{c|}{ Simulation-II [10\%] } \\
\cline { 3 - 6 } & & Shock & $\% \boldsymbol{\Delta}$ & Shock & \multicolumn{1}{c|}{$\boldsymbol{\Delta}$} \\
\hline GDPFC & 15255.095 & 15304.839 & 0.326 & 15354.725 & 0.653 \\
\hline GDPMP1 & 16320.344 & 16335.824 & 0.095 & 16351.257 & 0.189 \\
\hline GDPMP2 & 16370.419 & 16381.611 & 0.068 & 16392.717 & 0.136 \\
\hline GOVCON & 1711.912 & 1712.636 & 0.042 & 1713.364 & 0.085 \\
\hline INVEST & 1954.580 & 1949.413 & -0.264 & 1944.152 & -0.534 \\
\hline EXP & 2778.963 & 2788.240 & 0.334 & 2797.568 & 0.669 \\
\hline IMP & 3667.333 & 3676.923 & 0.261 & 3686.566 & 0.524 \\
\hline NITAX & 1115.324 & 1076.772 & -3.457 & 1037.992 & -6.934 \\
\hline PRVCON & 13542.222 & 13562.458 & 0.149 & 13582.738 & 0.299 \\
\hline
\end{tabular}

Source: Simulation Results

Note: GDPFC is GDP at factor cost, GDPGAP is GDP at market price, GDPMP1 is market price from expenditure side, GDPMP2 is market price from income side, GOVCON is government consumption, INVEST is investment in public and private sectors, EXP is export, IMP is import, NITAX is national income tax, and PRVCON is private consumption 


\subsection{The quantity of Domestic Output of Commodities}

Sales tax reducing reveals favorable impact on inland output of all the commodities except (C-AGRI) and (C-YARN), which is $\left(-8.22296 \mathrm{e}^{-4} \%,-0.002 \%\right)$ and $(-0.015 \%$ and $-0.031 \%)$ in both the experiments respectively. The production of all other selected commodities like C-MINE grows in by $0.081 \%$ and $0.163 \%$, C-FMAN by $0.069 \%$ and $138 \%$, C-TEXT by $0.544 \%$ and $1.087 \%$, C-LEAT by $0.345 \%$ and $0.690 \%$, C-MANF by $0.574 \%$ and $1.151 \%$, C-ENRG by $0.300 \%$ and $0.602 \%$, and C-SER by $0.069 \%$ and $0.138 \%$ in Test-I and Test-II (see, Table-02). The results illustrate that if the government reduces sales tax, production of internally produced commodities grows, which precedes household's consumption to increase and consequently the utility.

Table-02. Quantity of Domestic Output of Commodities

\begin{tabular}{|c|c|c|c|c|c|}
\hline \multirow{2}{*}{ Commodities } & \multirow{2}{*}{ Base } & \multicolumn{2}{|c|}{ Simulation-I [5\%] } & \multicolumn{2}{c|}{ Simulation-II [10\%] } \\
\cline { 3 - 6 } & & Shock & $\% \boldsymbol{\Delta}$ & Shock & $\% \boldsymbol{\Delta}$ \\
\hline C-AGRI & 7047.148 & 7047.090 & $-8.22296 \mathrm{e}^{-4}$ & 7047.012 & -0.002 \\
\hline C-MINE & 730.595 & 731.190 & 0.081 & 731.786 & 0.163 \\
\hline C-FMAN & 5073.711 & 5077.214 & 0.069 & 5080.723 & 0.138 \\
\hline C-YARN & 2480.102 & 2479.728 & -0.015 & 2479.342 & -0.031 \\
\hline C-TEXT & 1757.475 & 1767.032 & 0.544 & 1776.581 & 1.087 \\
\hline C-LEAT & 362.897 & 364.148 & 0.345 & 365.399 & 0.690 \\
\hline C-MANF & 4439.234 & 4464.712 & 0.574 & 4490.337 & 1.151 \\
\hline C-ENRG & 1956.650 & 1962.528 & 0.300 & 1968.423 & 0.602 \\
\hline C-SER & 9337.056 & 9343.528 & 0.069 & 9349.850 & 0.138 \\
\hline
\end{tabular}

Source: Simulation Results

Note: C-AGRI is agricultural products, C-MINE is mines, C-FMAN is food manufacturing, C-YARN is yarn, C-TEXT is textile products, C-LEAT is leather products, C-MANF is other manufacturing, C-ENRG is energy, and C-SER is services.

\subsection{Income of Households}

Sales tax reduction by $5 \%$ and $10 \%$ show the positive impact on all the sixteen groups of the households of the model. Obviously, real income of all the households increases, as a result consumption level also increases, which ultimately improves the welfare. In both the simulation tests, income growth of small, medium, and large farm rural households groups increases in the order of $\mathrm{H}$ RS1 by $0.248 \%$ and $0.496 \%, \mathrm{H}-\mathrm{RS} 234$ by $0.246 \%$ and $0.493 \%, \mathrm{H}-\mathrm{RH} 1$ by $0.233 \%$ and $0.467 \%, \mathrm{H}-\mathrm{RM} 234$ by $0.241 \%$ and $0.483 \%$ and H-RL1 $0.227 \%$ and $0.455 \%$, and similarly H-RL234 by $0.219 \%$ and $0.438 \%$ respectively. Whereas, income growth of the households of the category like H-RW1 is recorded by $0.285 \%$ and $0.571 \%, \mathrm{H}-\mathrm{RW} 234$ by $0.282 \% 0.0 .564 \%$ in both the experiments. Next four categories of the non-farm rural households 'income registered an increase in Test-I and II as in the sequence like $\mathrm{H}-\mathrm{RN} 1$ by $0.189 \%$ and $0.378 \%, \mathrm{H}-\mathrm{RN} 2$ by $0.151 \%$ and $0.302 \%, \mathrm{H}-\mathrm{RN} 3$ by $0.120 \%$ and $0.240 \%$, and $\mathrm{H}-$ RN4 by $0.068 \%, 0.137 \%$. Remaining four types of the urban households ' income also indicate increase after decrease in sales tax, which is noted as $0.180 \%, 0.360 \%, 0.164 \%, 0.329 \%, 0.134 \% .0 .267 \%$, and $0.074 \%, 0.148 \%$ for $\mathrm{H}-\mathrm{U} 1, \mathrm{H}-\mathrm{U} 2, \mathrm{H}-\mathrm{U} 3$, and $\mathrm{H}-\mathrm{U} 4$ respectively (see, Table-3). 
Table-3. Income of Households

\begin{tabular}{|c|c|c|c|c|c|}
\hline \multirow{2}{*}{ Households } & \multirow{2}{*}{ Base } & \multicolumn{2}{|c|}{ Simulation-I [5\%] } & \multicolumn{2}{c|}{ Simulation-II [10\%] } \\
\cline { 3 - 6 } & & Shock & $\% \Delta$ & Shock & $\%$ \\
\hline H-RS1 & 266.794 & 267.455 & 0.248 & 268.117 & 0.496 \\
\hline H-RS234 & 2162.746 & 2168.071 & 0.246 & 2173.408 & 0.493 \\
\hline H-RM1 & 14.465 & 14.499 & 0.233 & 14.532 & 0.467 \\
\hline H-RM234 & 863.868 & 865.953 & 0.241 & 868.043 & 0.483 \\
\hline H-RL1 & 196.529 & 196.976 & 0.227 & 197.424 & 0.455 \\
\hline H-RL234 & 932.712 & 934.754 & 0.219 & 936.800 & 0.438 \\
\hline H-RW1 & 200.420 & 200.991 & 0.285 & 201.563 & 0.571 \\
\hline H-RW234 & 620.021 & 621.768 & 0.282 & 623.520 & 0.564 \\
\hline H-RN1 & 400.802 & 401.559 & 0.189 & 402.317 & 0.378 \\
\hline H-RN2 & 556.320 & 557.160 & 0.151 & 558.000 & 0.302 \\
\hline H-RN3 & 754.234 & 755.140 & 0.120 & 756.047 & 0.240 \\
\hline H-RN4 & 1297.821 & 1298.707 & 0.068 & 1299.596 & 0.137 \\
\hline H-U1 & 232.361 & 232.779 & 0.180 & 233.197 & 0.360 \\
\hline H-U2 & 565.192 & 566.120 & 0.164 & 567.051 & 0.329 \\
\hline H-U3 & 1207.981 & 1209.594 & 0.134 & 1211.210 & 0.267 \\
\hline H-U4 & 6499.509 & 6504.302 & 0.074 & 6509.105 & 0.148 \\
\hline
\end{tabular}

Source: Simulation Results

Note: H-RS1 is households rural small of category-1, H-RS234 is households rural small of category-2,3, \& 4, H-RM1 is households rural medium of category-1, H-RM234 is households rural medium of category-2,3, \& 4, H-RL1 is household rural large of category-1, H-RL234 is households rural large of category-2,3,\& 4, H-RW1 is households farm workers of category-1, HRW234 is households farm workers of category-2,3,\& 4, H-RN1, H-RN2, H-RN3, and H-RN4 are households rural non-farm category-1, 2,3, \& 4 respectively, and $\mathrm{H}-\mathrm{U} 1, \mathrm{H}-\mathrm{U} 2, \mathrm{H}-\mathrm{U} 3$, and $\mathrm{H}-\mathrm{U} 4$ are households urban of category-1,2,3, \& 4 .

\subsection{Average Price of Factors}

Factor's average price presents positive impact in both the experiments. It is noticed in case of land $0.252 \%$ and $0.504 \%$, while in case of capital $0.351 \%$ and $0.704 \%$ in both the experiments respectively (see, Table-4).

Table-4. Average Price of Factors

\begin{tabular}{|c|c|c|c|c|c|}
\hline \multirow{2}{*}{ Factors } & \multirow{2}{*}{ Base } & \multicolumn{2}{|c|}{ Simulation-I [5\%] } & \multicolumn{2}{c|}{ Simulation-II [10\%] } \\
\cline { 3 - 6 } & & Shock & $\% \mathbf{\Delta}$ & Shock & $\% \boldsymbol{\Delta}$ \\
\hline $\mathrm{L}$ & 1.059 & 1.059 & & 1.059 & \\
\hline $\mathrm{N}$ & 1.388 & 1.392 & 0.252 & 1.395 & 0.504 \\
\hline $\mathrm{K}$ & 0.965 & 0.968 & 0.351 & 0.972 & 0.704 \\
\hline
\end{tabular}

\subsection{Balance of Trade}

Reducing sales tax indicates negative impact on exports for goods like C-AGRI (agricultural products), C-MINE mines, C-FMAN (food manufacturing), C-YARN (yarn), and C-SER (services), while positive impact on C-TEXT (textile), C-LEAT (leather), and C-MANF (other manufacturing) in both the experiments. The negative growth is observed in C-AGRI by $0.654 \%$ and $1.304 \%$, in C-MINE by $0.545 \%$, $1.088 \%$, in C-FMAN by $0.258 \%, 0.515 \%$, in C-YARN by $0.284 \%, 0.569 \%$, and in C-SER by $0.003 \%, 0.006 \%$. Which indicates that households consume more quantity of these commodities at home, which results into increase in their welfare. Whereas, positive growth is noted in C-TEXT by $0.642 \%$ and $1.283 \%$, in C-LEAT by $0.512 \%, 1.024 \%$, and in C-MANF by $0.990 \%, 1.989 \%$ (see Table- 5 ). 
The model shows, the impact of sales tax reduction is positive on import of all commodities in both the experiments. It indorses increase in household's real income and thus increase in consumption of imports which means increase in welfare level. Growth in import in Test-I (5\%) and Test-II (10\%) is recorded in C-AGRI by $0.672 \%$ and $1.348 \%$, in C-MINE by $0.832 \%$ and $1.671 \%$, in C-FMAN by $0.499 \%$ and $1.001 \%$, in C-YARN by $0.412 \%$ and $0.825 \%$, in C-TEXT by $0.172 \%$ and $0.345 \%$, in C-LEAT by $0.021 \%$ and $0.042 \%$, in C-MANF by $0.038 \%$ and $0.076 \%$ ], and in C-SER by $0.172 \%, 0.344 \%$ respectively (see Table-6).

Table-5 Quantity of Exports for Commodities

\begin{tabular}{|c|c|c|c|c|c|}
\hline \multirow{2}{*}{ Commodities } & \multirow{2}{*}{ Base } & \multicolumn{2}{|c|}{ Simulation-I [5\%] } & \multicolumn{2}{c|}{ Simulation-II [10\%] } \\
\cline { 3 - 6 } & & Shock & $\% \boldsymbol{\Delta}$ & Shock & $\% \boldsymbol{\Delta}$ \\
\hline C-AGRI & 82.769 & 82.228 & -0.654 & 81.690 & -1.304 \\
\hline C-MINE & 59.731 & 59.406 & -0.545 & 59.082 & -1.088 \\
\hline C-FMAN & 318.911 & 318.088 & -0.258 & 317.267 & -0.515 \\
\hline C-YARN & 499.595 & 498.175 & -0.284 & 496.753 & -0.569 \\
\hline C-TEXT & 999.712 & 1006.129 & 0.642 & 1012.542 & 1.283 \\
\hline C-LEAT & 97.557 & 98.056 & 0.512 & 98.556 & 1.024 \\
\hline C-MANF & 435.110 & 439.416 & 0.990 & 443.763 & 1.989 \\
\hline C-SER & 272.101 & 272.094 & -0.003 & 272.084 & -0.006 \\
\hline
\end{tabular}

Source: Simulation Results

Table-6 Quantity of Imports for Commodities

\begin{tabular}{|c|c|c|c|c|c|}
\hline \multirow{2}{*}{ Commodities } & \multirow{2}{*}{ Base } & \multicolumn{2}{|c|}{ Simulation-I [5\%] } & \multicolumn{2}{c|}{ Simulation-II [10\%] } \\
\cline { 3 - 6 } & & Shock & $\% \boldsymbol{\Delta}$ & Shock & $\% \boldsymbol{~}$ \\
\hline C-AGRI & 160.616 & 161.696 & 0.672 & 162.781 & 1.348 \\
\hline C-MINE & 406.733 & 410.119 & 0.832 & 413.530 & 1.671 \\
\hline C-FMAN & 421.239 & 423.343 & 0.499 & 425.457 & 1.001 \\
\hline C-YARN & 108.664 & 109.111 & 0.412 & 109.560 & 0.825 \\
\hline C-TEXT & 160.194 & 160.469 & 0.172 & 160.746 & 0.345 \\
\hline C-LEAT & 11.901 & 11.904 & 0.021 & 11.906 & 0.042 \\
\hline C-MANF & 2340.378 & 2341.263 & 0.038 & 2342.146 & 0.076 \\
\hline C-SER & 335.117 & 335.693 & 0.172 & 336.270 & 0.344 \\
\hline
\end{tabular}

Source: Simulation Results

\section{Conclusion}

To analyze the impact of sales tax on macroeconomic indicators of Pakistan Economy, this analysis employed Computable General Equilibrium Model and used Social Accounting Matrix 2010-11 to investigate the impact of reducing sales tax on macroeconomic indicators like GDP, Exports, Imports, Balance of Trade, National Income, Investment, etc. For this target, two simulations are experimented for reducing sales tax by $5 \%$, and by $10 \%$. Trade elasticities for goods and services in Pakistan have been derived from Ahmed et al. (2008). Two tests are operated to measure the impact of reducing sales tax on above mentioned variables. Sales tax have been decreased by $5 \%$ in Simulation-I and $10 \%$ in Simulation-II.

The experiment shows that in general, this action placed positive impact on all the above-stated macroeconomic indicators. Though there are few variables that show that reducing sales tax effect negative as well, but positive impact is noticed on important indicators like GDP at Factor Price, GDP at Market price from Spending Side, GDP at Market Price from Income Side, Government 
Consumption, Private Consumption, Exports, Imports. Therefore, there occurs an improvement in various economic activities. Whereas, a very minor effect on Investment and Net Indirect Taxes. Similarly, by reducing sales tax except agriculture and yarn, quantity of domestic output of all other commodities like mines, food manufacturing, textile, leather products, other manufacturing, energy, and services registers positive impact. Moreover, this policy impacts favorably on all the households like rural small, medium, large, farm workers, non-farm workers, and urban as categorized in the model. Likewise, the outcomes of the factor's like land and capital also show increase in their average prices. Balance of trade reveals favorable in both the simulations in the sense that decrease in exports of few products like agriculture, mines, food manufacturing, yarn, and services reflects high availability of these products at home along with increase in import of all of the commodities indicates boost in welfare due to high consumption of Pakistani peoples. Keeping all the findings in view, the investigation suggests that a decrease in sales tax can be initiated steadily, which results into increase in macroeconomic indicators, welfare, prosperity, development and growth.

\section{Referencias}

1. Ahmed, Vaghar, and Cathal O'Donoghue. 2009. "External Shocks in a Small Open Economy: A CGEMicrosimulation Analysis." Department of Economics, National University of Ireland, Galway. Working Paper No. 0142.

2. Ahmad, S., Sial, H. M., \& Ahmad, N. (2018). Indirect taxes and economic growth: An empirical analysis of Pakistan. Pakistan Journal of Applied Economics, 28(1), 65-81.

3. Arisoy, I., and I. Unlukaplan, 2010, Tax composition and growth in Turkey: An empirical analysis, International Research Journal of Finance and Economics, 59: 50-61.

4. Barro, R. J., Sala-i-Martin, \& Xavier. (1991). Public Finance In Models Of Economic Growth. The Review of Economic Studies, (59(4)), 645.

5. Bhatti, A., Batool, Z., \& Naqvi, H. (2015). Impact of Tax and Transfers on Income Inequality and Budget Deficit: A CGE Analysis for Pakistan. Available at SSRN 2702750.

6. Bhatti, A. A., Batool, Z., \& Naqvi, H. A. (2015). Fiscal policy and its role in reducing income inequality: a CGE analysis for Pakistan. The Pakistan Development Review, 843-862.

7. Bleaney, M., Gemmell, N., \& Kneller, R. (2000). Testing The Endogenous Growth Model- Public Expenditure- Taxation And Growth Over The Long-Run. Canadian Journal of Economics, 34(1)(00), 36-57.

8. Dehghan, M. and Nonejad, M., 2015. The Impact of Tax Rates on Economic Growth of Iran in the Years 1981-2010. Journal of Finance and Accounting, 3(6), pp. 220-226

9. Dehghan, M. and Nonejad, M., 2015. The Impact of Tax Rates on Economic Growth of Iran in the Years 1981-2010. Journal of Finance and Accounting, 3(6), pp. 220-226

10.Dorosh Paul, Niazi Muhammad Khan, and Nazili Hina, (2015). A social accounting matrix for Pakistan, 2010-11: Methodology and results. Pakistan Institute of Development Economics. Islamabad.

11.Fadare, S. O. (2010). Recent Banking Sector Reforms And Economic Growth In Nigeria. Middle Eastern Finance and Economics, 8(8), 146-160.

12.Naqvi, H. A., Hakeem, M. M., \& Naeem, R. A. (2011). Impact of Agricultural Income Tax on Household Welfare and Inequality: Pakistan A Case-in-Point. International Journal of Business and Social Science, 2(6), 103-118.

13.Iqbal, N., Azam, M. F. and Shinwari, S., 2015. Empirical Analysis of Tax Revenues and Its Impact on Economic Growth of Pakistan. Journal of Economics and Sustainable Development, 6(1), pp. 110117.

14.Lofgren, H., Harris, R. L., \& Robinson, S. (2002). A standard computable general equilibrium (CGE) model in GAMS (Vol. 5). Intl Food Policy Res Inst.

15. Mashkoor, M., S. Yahya and S.A. Ali, 2010, Tax revenue and economic growth: An empirical analysis for Pakistan, World Applied Science Journal, 10(11): 1283-1289. 
16.Nmesirionye, J. A., Jones, E., \& Onuche, E. V. S. (2019). Impact of indirect taxes on economic performance of Nigeria (1994-2017). European Journal of Accounting, Finance and Investment, 5(4), 32-39.

17.Papageorgiou, D. (2012). Fiscal Policy Reforms In General Equilibrium: The Case Of Greece. Journal of Macroeconomics, 34(2), 504-522.

18.Phiri, A., 2016. The Growth Trade-off between Direct and Indirect Taxes in South Africa: Evidence from a STR Model. Managing Global Transitions, 14(3), pp. 233-250.

19.Poulson, B.W., and J.G. Kaplan, 2008, State income taxes and economic growth, Cato Journal, 28(1): 53-71. 